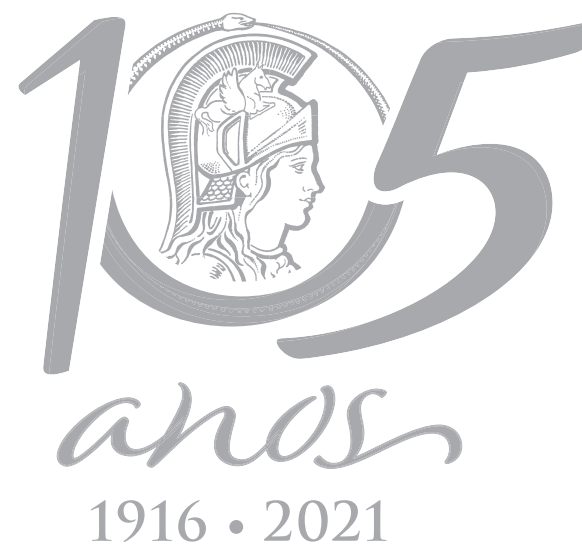

\title{
MICROBIOLOGY
}

\section{Determination of antimicrobial and antimutagenic properties of some Schiff bases}

\author{
HATICE OGUTCU, SEHER MERAL, SELCUK CEKER, AYSEN ALAMAN AGAR \& \\ GULERAY AGAR
}

\begin{abstract}
In this study, we aimed to investigate for the first time antimicrobial and antimutagenic activities new two Schiff bases, obtained from a primary amine (p-toluidine, o-toluidine) and an aldehyde (Helicin). Synthesized compounds characterized with elemental analysis, fourier transform infrared spectroscopy, ultraviolet-visible spectrophotometry. ${ }^{1} \mathrm{H}-{ }^{13} \mathrm{C}$ nuclear magnetic resonance spectroscopy. Antimutagenic activity was evaluated by micronuclei assay. Antimicrobial activity of Schiff bases have been demonstrated against pathogenic four Gram-positive bacteria (Staphylococcus aureus, Staphylococcus epidermis, Micrococcus luteus, Bacillus cereus) and four Gramnegative bacteria (Pseudumonas aeroginosa, Salmonella typhi H, Brucella abortus, Escherichia coli) and two yeasts (Candida albicans and Saccharomyces cerevisiae). The results showed that both Schiff bases have antimutagenic activity. Especially, high concentration (20 $\mu \mathrm{M})$ of (E)-2-(hydroxymethyl)-6-(2-((p-tolylimino)methyl) phenoxy)tetrahydro-2H-pyran-3,4,5-triol (Compound I) and (E)-2-(hydroxymethyl)-6(2-((o-tolylimino)methyl)phenoxy)tetrahydro-2H-pyran-3,4,5-triol (Compound II) have strong antimutagenic activity against aflatoxin $\mathrm{B}_{1}$. On the other hand, both of studied compounds were found effective against pathogenic bacteria and yeasts. Compound I exhibited more activity against P. aeroginosa, S aureus, S.typhi $H$ and C. albicans comparable to Compound II and standard antibiotics. Additionally, Compound II showed better inhibitory activity than Compound I against Candida albicans and Br. Abortus. Therefore, these compounds can be used in phytotherapeutic due to theirs antimutagenic and antimicrobial activities.
\end{abstract}

Key words: Anti-microbial activity, elemental analysis, genotoxicity, helicin, pathogenic strains, Schiff bases.

\section{INTRODUCTION}

Schiff bases are colorful organic compounds use as pigment in dye, cosmetic industry and synthesize easily, have excellent properties such as high thermal stability, biological activities, form metal complexes point out in numerous field (Dhar \& Taploo 1982, Bringmann et al. 2004, Zabulica et al. 2013, Tanak et al. 2014). Schiff bases are known as electron-donating groups presence of nitrogen atom in which provide to form complexes with metals and also in many enzymatic reaction appear as an intermediate product (Metzler et al. 1954, Snell \& Jenkins 1959, Cordes \& Jencks 1962). Recently, several studies have demonstrated that Schiff bases have biological activities such as antimutagenic, antibacterial (Nartop et al. 2012, Sarı et al. 2013). However, antimutagenic and antibacterial effects of these compounds has not been reported up to the present. Therefore, in this study, we aimed to investigate for the first time antimicrobial and antimutagenic activities new two Schiff bases, obtained from a primary amine ( $p$-toluidine, 
o-toluidine) and an aldehyde (Helicin). Helicin, which is named also salicylaldehyde- $\beta-D$ glucoside, is a natural product obtained from salisin. Helicin is a chiral molecule due to asymmetric carbon and also the aldehydic group of helicin has been used to synthesize of Schiff base, that imine bond occur upon leave a water molecule as a by-product (Mishra et al. 2017). Mutagenic and antimutagenic effects of new two Schiff bases were evaluated by micronuclei (MN) assay. Antimicrobial activity was complexing the well diffusion method (Nartop et al. 2012, Sarı et al. 2013, Altundas et al. 2016).

\section{MATERIALS AND METHODS}

\section{Synthesis of title compounds}

Schiff bases (Moffett 1963) were prepared by refluxing a mixture of solution containing helicin $(0,09 \mathrm{mmol})$ in ethanol $(20 \mathrm{~mL})$ and a solution containing a primary amine ( $p$-toluidine, o-toluidine 0,09 $\mathrm{mmol}$ ) in ethanol $(20 \mathrm{~mL})$. The reaction mixture was stirred for 5 hours under reflux. Synthesized compounds were evaporated at room temperature. Melting point for Compound I is 380-392 $\mathrm{K}$ and Compound II is 385-395 K.

\section{Antimutagenic activity}

Whole blood samples from four healthy nonsmoking donors between the ages of 23 and 25 were used for the enzyme assays and separated lymphocyte cells from same blood samples were used for MN assay (the study was approved by Ataturk University, Medical Faculty Ethical Review Board). For MN assay, $3 \mathrm{~mL}$ of whole peripheral blood from each donor was collected by venepuncture. $0.3 \mathrm{~mL}$ of heparin was added to the each of the blood samples and the samples were homogenized. $0.5 \mathrm{~mL}$ of heparinized whole blood samples were cultured in $7 \mathrm{~mL}$ of RPMI-1640 contained 15\% heat-inactivated fetal calf serum, $1 \%$ streptomycin, $1 \%$ penicillin, 2\% glutamine and $2 \%$ phytohemagglutinin. To this solution, at 24th hour, the agents to be tested and aflatoxin $\mathrm{B}_{1}(5 \mu \mathrm{M})\left(\mathrm{AFB}_{1}\right)$ was added and cultured at $37^{\circ} \mathrm{C}$ for $42 \mathrm{~h}$ in a $5 \% \mathrm{CO}_{2}$ moist atmosphere (Singh et al. 1988). AFB and the agents to be tested were dissolved in $0.5 \%$ dimethyl sulfoxide (DMSO). AFB 1 (5 $\mu \mathrm{M})$, compound 1 (Comp-1) and different concentration of comp-1 (5 $\mu \mathrm{M}$, $10 \mu \mathrm{M}$ and $20 \mu \mathrm{M}$,) were added to the cultures just before incubation. Same protocols were done for compound 2 (Comp-2). During the incubation period, cytochalasin B $(3 \mu \mathrm{g} / \mathrm{mL})$ was added to the whole blood samples at $44 \mathrm{~h}$ incubation. After $72 \mathrm{~h}$ incubation, the cells were harvested by centrifugation (1000 rpm, $10 \mathrm{~min}$ ), the supernatant was collected and immediately assayed for enzyme activities (Orhan et al. 2016). $6 \mathrm{~mL}$ of $0.05 \mathrm{M} \mathrm{KCl}$ was added to the pellet containing lymphocyte cells, vortexed and incubated at $37^{\circ} \mathrm{C}$ for 7 min. After the incubation period, the lymphocyte cells were harvested by centrifugation (1000 rpm, $10 \mathrm{~min}$ ) and the supernatant was removed. $6 \mathrm{~mL}$ of fresh fixative solution [acetic acid and methanol (1:3) was added drop by drop to the pellet. The fixation procedure was repeated three times and the tube was centrifuged (1000 rpm, $10 \mathrm{~min}$ ). The cell pellet was re-suspended in $1 \mathrm{~mL}$ of fresh fixative solution, and then the suspension was dropped on to clean and labelled microscope slides and incubated at room temperature for $72 \mathrm{~h}$. After the incubation period, the slides were stained with $5 \%$ giemsa dye solution for $10 \mathrm{~min}$ and excess giemsa dye was removed with distilled water. The slides were air-dried, and only binucleated cells were scored for MN analysis. For each experimental group, approximately 1000 bi-nucleated cells were analyzed for the presence of MN (Ceker et al. 2015). 


\section{Antimicrobial activity}

\section{Test microorganisms}

The pathogenic bacterial and yeasts were used; bacterial cultures chosen were Staphylococcus aureus ATCC25923, Escherichia coli ATCC1280, Salmonella typhi H NCTC901.8394, Pseudomonas aeroginosa sp., Brucella abortus RSKK03026, Staphylococcus epidermis sp., Micrococcus luteus ATCC9341, Bacillus cereus RSKK-863, and Candida albicans Y-1200-NIH and Saccharomyces cerevisiae sp.

\section{Detection of antimicrobial activity}

These synthesized compounds (compound I and II) were examined for their antimicrobial activity by the well-diffusion method (Sarı et al. 2013) against pathogenic four Gram-positive bacteria (S. aureus, S. epidermis, M. Luteus, B. cereus) and four Gram-negative bacteria ( $P$. aeroginosa, S. typhi H, E. coli, Br. abortus) and two yeast (C. albicans and $S$. cerevisiae). These compounds were kept dry at room temperature and dissolved $(0.25 \mu \mathrm{g} / \mu \mathrm{L})$ in DMSO. DMSO was used as both solvent and control. It was found to have no antimicrobial activity against any of the tested organisms 1\% (v/v) of a $24 \mathrm{~h}$ broth culture containing $10^{6} \mathrm{CFU} / \mathrm{mL}$ was placed in the sterile Petri plates. Mueller-Hinton Agar (MHA) (15 mL) kept at $45^{\circ} \mathrm{C}$ was then poured into the Petri-dishes and allowed to solidify. Then wells of $6 \mathrm{~mm}$ diameter were punched carefully by using a sterile cork borer and were entirely filled with the test solutions. The plates were incubated for $24 \mathrm{~h}$ at $37^{\circ} \mathrm{C}$. On completion of the incubation period, the mean value obtained for the two holes was used to calculate the zone of growth inhibition of each sample. Pathogenic bacterial cultures and yeast were tested for resistance to five antibiotics produced by Oxoid Lt., Basingstoke, UK. These were: Ampicillin (prevents the growth of Gram-negative bacteria), Nystatin (binds to sterols in the fungal cellular membrane and alters the permeability allowing leakage of the cellular contents), Kanamycin, Sulfamethoxazole (a bacteriostatic antibacterial agent that interferes with folic acid synthesis in susceptible bacteria), Amoxycillin (a $\beta$-lactam antibiotic used to treat bacterial infections caused by sensitive microorganisms).

\section{RESULTS}

Schiff bases (Moffett 1963) were obtained by condensation of helicin and primary amine (p-toluidine, o-toluidine) in ethanol solution. Structures of Schiff bases were analyzed with elemental analysis, FT-IR, UV-Vis, ${ }^{13} \mathrm{C}$ and ${ }^{1} \mathrm{H}$ NMR spectroscopy. The data are agreeable with predicted structures as shown in Figure 1.

Spectral data of title compounds are given Table I. In this study, carbonyl bond of helicin turned to imine bond together leave a water molecule by reflux in ethanol. Due to electron with drawing hydroxyl groups of helicin reaction occurred mild conditions with high yield and purity. The $\mathrm{C}=\mathrm{N}$ stretching vibrations which usually are expected in 1600-1700 $\mathrm{cm}^{-1}$ region (Anar et al. 2016) and are characteristic peaks for Schiff bases. In FT-IR spectrum of synthesized compounds sharp peaks were observed at 1621$1624 \mathrm{~cm}^{-1}$, that may prove to occur $\mathrm{C}=\mathrm{N}$ bond. Also, broad $\mathrm{OH}$ vibrations were appeared at 3394-3372 and the spectral and between at 2850-2920 $\mathrm{cm}^{-1}$ were occurred based on aliphatic $\mathrm{C}-\mathrm{H}$ vibration. The imine proton of Schiff bases in ${ }^{1} \mathrm{H}$ NMR spectrum was determined at 8.899-9.006 ppm $(\mathrm{s}, 1 \mathrm{H})$. The aromatic protons exhibited signal at about 6.499-8.083 ppm. In ${ }^{13} \mathrm{C}$ NMR spectrum, imin carbon was appeared at 155-157 ppm. In UV spectra of synthesized Schiff bases recorded in ethanol and observed similar peaks by the 
<smiles>O=Cc1ccccc1OC1OC(CO)C(O)C(O)C1O</smiles>

Helicin
$\mathrm{H}_{2} \mathrm{~N}$

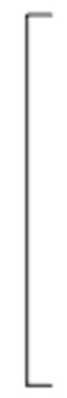
p-toluidine<smiles>Cc1ccc(/N=C/c2ccccc2OC2OC(CO)C(O)C(O)C2O)cc1</smiles>

(E)-2-(hydroxymethyl)-6-(2-((p-tolylimino)methyl) phenoxy)tetrahydro-2H-pyran-3,4,5-triol (Compound I)

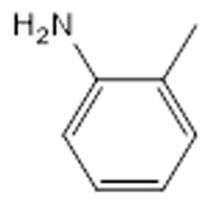

o-toluidine

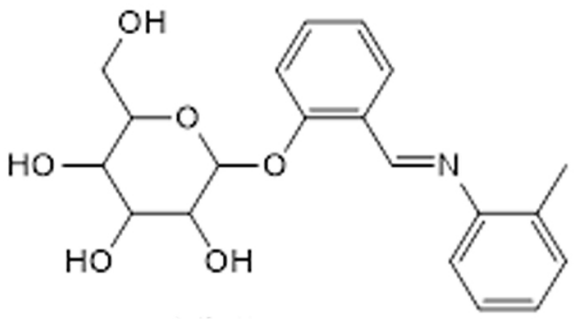

(E)-2-(hydroxymethyl)-6-(2-((otolylimino)methyl)phenoxy) tetrahydro-2H-pyran-3,4,5-triol (Compound II)

\section{Figure 1. Structures and abbreviations of synthesized Schiff bases.}

reason of same chemical groups. The peak was shown about $330 \mathrm{~nm}$ and $340 \mathrm{~nm}$ for Compound I and Compound II based on $n-\pi^{*}$ transitions of imine bond.

When we evaluate the data obtained in MN test system, it can be concluded that the simultaneous treatments of $\mathrm{AFB}_{1}$ with almost all concentrations of two compounds have a significant anti-genotoxic potential (Table II). Namely, two compounds reduced the number of $M N$, and that reduction was found to be statistically significant $(p<0.05)$. Compounds 2 more effective than compounds 1 (Table II).

The synthesized compounds (compound I and II) were screened for in vitro anti-bacterial and anti-fungal activity in DMSO solvent as a control substance. The compounds were tested with the same concentrations in DMSO solution $(0.25 \mu \mathrm{g} / \mu \mathrm{L})$. All the synthesized compounds and anti-biotics exhibited varying degrees of inhibitory effects on the growth of different tested pathogenic microorganisms (Table III).

The results of antibacterial screening indicated Compound I showed activity against most of the strains both gram-positive ( $S$. aureus $(20 \mathrm{~mm})$ ) and gram negative bacteria (S. typhi H (20mm), P. aeroginosa $(15 \mathrm{~mm}))$. S. aureus is a clinically important pathogen as it causes various types of infections (Halling et al. 2005). Salmonella serovars cause very diverse clinical symptoms, from asymptomatic infection to serious typhoid-like syndromes in infants or certain highly susceptible animals (Altundas et al. 2010). Compound II showed activity against most of C. albicans $(30 \mathrm{~mm})$. Additionally, Compound II were potent growth inhibitors against $\mathrm{Br}$. abortus with a zone value of 13 $\mathrm{mm}$. Br. abortus is a gram-negative bacterium that causes premature abortion of cattle fetus (Halling et al. 2005), in addition it is a human pathogen which is a very serious, debilitating 
Table I. Data of elementel analysis, FT-IR, UV-vis, 1H and 13C NMR spectra of Compounds.

\begin{tabular}{|c|c|c|c|}
\hline \multicolumn{2}{|c|}{ Compounds / Analysis results } & \multirow{2}{*}{$\begin{array}{l}\text { Compound } 1 \\
59.50(61.69) \\
\end{array}$} & \multirow{2}{*}{$\begin{array}{l}\text { Compound } 2 \\
58.16(64.33) \\
\end{array}$} \\
\hline & C & & \\
\hline (Calcd) \% & $\mathrm{H}$ & $6.28(5.95)$ & $6.22(6.21)$ \\
\hline & N & $3.80(3.60)$ & $3.43(3.75)$ \\
\hline \multirow{4}{*}{$\begin{array}{l}\text { FT-IR vibration frequences } \\
\qquad\left(\mathrm{cm}^{-1}\right)\end{array}$} & $-\mathrm{OH}$ & 3394 & 1621 \\
\hline & $\mathrm{C}-\mathrm{H}$ & $2850-2920$ & $2880-2920$ \\
\hline & $C=N$ & 1621 & 1624 \\
\hline & $\mathrm{C}-\mathrm{O}$ & 1074 & 1079 \\
\hline UV-Vis. values $(\mathrm{nm})$ & $\lambda_{\max }$ & 340 & 330 \\
\hline \multirow{3}{*}{ H NMR } & $H C=N$ & 9.006 & 8.899 \\
\hline & $\mathrm{Ar}-\mathrm{H}$ & $8.039-7.129$ & $8.083-6.499$ \\
\hline & $\mathrm{O}-\mathrm{H}$ & $5.092-4.583$ & $5.092-4.588$ \\
\hline \multirow{3}{*}{ C NMR } & $C=N$ & 155.659 & 157.859 \\
\hline & $C=C$ & $157.859-116.715$ & 155.885-118.491 \\
\hline & $\mathrm{C}-\mathrm{O}$ & 101.589-61.149 & $101.482-61.125$ \\
\hline
\end{tabular}

FT-IR: Fourier Transform Infrared Spectrometer, UV-Vis: Ultraviolet-Visible Spectrophotometry, NMR: Nuclear Magnetic Resonance, C NMR: Carbon-13 Nuclear Magnetic Resonance.

and sometimes chronic disease that may affect a variety of organs (Sauret \& Vilissova 2002). The antimicrobial activity of these compounds was also compared with seven commercial antibiotics (Kanamycin, Sulfamethoxazole, Ampicillin, Chloramphenicol, Ciprofloxacin, Amoxycillin, Sulbactam and Nystatin). It was seen that the synthesized compounds were effective as the antibiotics mentioned.

\section{DISCUSSION}

Schiff bases have increasing importance in the preparation of some drugs, production of dye, in the electronics industry, in the plastics industry, in cosmetics, in polymer production and in various fields such as analytical chemistry, liquid crystal technology. Schiff bases have biological and structural importance. For this reason, researchers are so working on Schiff bases (Şakiyan et al. 2014, Nartop et al. 2014). It is known that the use of chemotherapeutic property. Because of these properties of Schiff bases have important role pharmaceutical industry and some different industry. Especially, biological activities on biological systems of Schiff bases are engaging attention of researchers (Sarı et al. 2013, Altundas et al. 2010, Anar et al. 2016). A large number of Schiff bases and their complexes are of significant interest due to their diverse biological activities including anti-tumor, antibacterial, fungicidal and anticarcinogenic (Nartop et al. 2014) showed that new synthesized chemical complex materials have anti-cancer and anti-oxidant activities including azo-azomethine complexes. In additions, they showed that the antiproliferative effects of the azo-azomethine complexes on human cervical cancer (HeLa) cells. 
Table II. The effects of AFB1 and Comp 1 / Comp 2 on MN.

\begin{tabular}{|c|c|c|c|}
\hline Test Items & Concentrations & $\begin{array}{c}\text { MN Numbers } \pm \text { S.E. } \\
\text { Comp 1 }\end{array}$ & $\begin{array}{c}\text { MN Numbers } \pm \text { S.E. } \\
\text { Comp 2 }\end{array}$ \\
\hline Control (-) & & $1.82 \pm 0.06^{\mathrm{a}}$ & $1.82 \pm 0.06^{\mathrm{a}}$ \\
\hline Control (+) & $5 \mu \mathrm{M}$ & $3.50 \pm 0.02^{\mathrm{d}}$ & $3.50 \pm 0.02^{\mathrm{d}}$ \\
\hline Comp 1/ Comp 2 & $10 \mu \mathrm{M}$ & $1.96 \pm 0.04^{\mathrm{a}}$ & $1.91 \pm 0.03^{\mathrm{a}}$ \\
\hline $\mathrm{AFB}_{1}+$ Comp & $5 \mu \mathrm{M}+5 \mu \mathrm{M}$ & $3.06 \pm 0.05^{\mathrm{c}}$ & $3.00 \pm 0.03^{\mathrm{c}}$ \\
\hline $\mathrm{AFB}_{1}+$ Comp & $5 \mu \mathrm{M}+10 \mu \mathrm{M}$ & $2.62 \pm 0.07^{\mathrm{bc}}$ & $2.44 \pm 0.08^{\mathrm{b}}$ \\
\hline $\mathrm{AFB}_{1}+$ Comp & $5 \mu \mathrm{M}+20 \mu \mathrm{M}$ & $2.34 \pm 0.02^{\mathrm{b}}$ & $2.22 \pm 0.04^{\mathrm{ab}}$ \\
\hline
\end{tabular}

$\mathrm{AFB}_{1}$ was used as positive controls for human peripheral lymphocytes.

$a, b, c, d$ Values of MN are significantly different compared to negative control $(P<0.05)$.

Table III. Biological activity of compounds (compound I and II) and standard reagents (diameter of zone inhibition $(\mathrm{mm}))$.

\begin{tabular}{|c|c|c|c|c|c|c|c|c|c|}
\hline \multirow{2}{*}{\multicolumn{2}{|c|}{$\begin{array}{c}\text { Compound } \\
\text { Microorganisms }\end{array}$}} & \multirow{3}{*}{$\begin{array}{c}\text { Compound } \\
-1-\end{array}$} & \multirow{3}{*}{$\begin{array}{c}\underset{-2-}{C} \\
15\end{array}$} & \multicolumn{6}{|c|}{ Positive Control } \\
\hline & & & & \multirow{2}{*}{$\begin{array}{c}\mathbf{K} 30 \\
14\end{array}$} & \multirow{2}{*}{$\begin{array}{c}\text { SXT25 } \\
18\end{array}$} & \multirow{2}{*}{$\begin{array}{c}\text { AMP10 } \\
8\end{array}$} & \multirow{2}{*}{$\begin{array}{c}\text { AMC30 } \\
15\end{array}$} & \multirow{2}{*}{$\begin{array}{c}\text { NYS100 } \\
-\end{array}$} & \multirow{2}{*}{$\begin{array}{c}\text { SCF } \\
-\end{array}$} \\
\hline \multirow{4}{*}{$\underset{(-)}{\text { Gram }}$} & P. aeroginosa & & & & & & & & \\
\hline & S. typhi H & 20 & 16 & 20 & 17 & 11 & 19 & - & - \\
\hline & Br. abortus & - & 13 & - & - & - & - & - & 12 \\
\hline & E. coli & - & - & 25 & 18 & 10 & 14 & - & - \\
\hline \multirow{4}{*}{$\underset{(+)}{\operatorname{Gram}}$} & S. aureus & 20 & - & 25 & 24 & 30 & 30 & - & - \\
\hline & S. epidermis & 15 & 20 & - & - & - & - & - & - \\
\hline & M. luteus & 10 & - & - & - & - & - & - & - \\
\hline & B. cereus & 10 & 15 & - & - & - & - & - & - \\
\hline \multirow{2}{*}{ Yeast } & C. albicans & 24 & 30 & - & - & - & - & 20 & - \\
\hline & $\begin{array}{c}\text { Saccharomyces } \\
\text { cerevisiae }\end{array}$ & 15 & 17 & - & - & - & - & - & - \\
\hline Control & DMSO & - & - & - & - & - & - & - & - \\
\hline
\end{tabular}

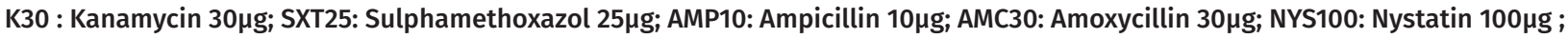
SCF: Sulbactam $(30 \mu \mathrm{g})+$ Cefoperazona $(75 \mu \mathrm{g})$.

Additionally, compounds (compound I and II) exhibited very good antimicrobial activity against a wide range of pathogenic microorganisms. The synthesized compounds were as effective as the antibiotics mentioned. Compounds I and II were synthesised from helicin with $\mathrm{p}$ - and o-toluidine. Helicin is a polar molecule, but $\mathrm{p}$-toluidine or o-toluidine may provide lipophilic character which enhances antimicrobial activity, as much as. Therefore, both compounds showed similar effect. 


\section{REFERENCES}

ALTUNDAS A, ERDOGAN Y, OGUTCU H, KIZIL HE \& AGAR G. 2016. Synthesis and In-vitro Antimicrobial and Anti-mutagenic Activities of some Novel 2-(2-Hydroxybenzylideneamino)5,7-dihydro-4H-thieno[2,3-c]pyran-3-carbonitrile Derivatives. Fresenius Environ Bull 25: 5411-5418.

ALTUNDAS A, SARI N, COLAK N \& ÖGÜTCÜ H. 2010. Synthesis and biological activity of new cycloalkylthiophene-Schiff bases and their $\mathrm{Cr}$ (III) and Zn (II) complexes. Med Chem Res 19: 576-588.

ANAR M, ÖZKAN EH, ÖĞÜTÇÜ H, AĞAR G, ŞAKIYAN I \& SARI N. 2016. Useful agents against aflatoxin B1-antibacterial azomethine and $\mathrm{Mn}$ (III) complexes involving L-Threonine, L-Serine, and L-Tyrosine. Artif Cells Nanomed Biotechnol 44: 853-858.

BRINGMANN G, DREYER M, FABER JH, DALSGAARD PW, STAERK D, JAROSZEWSKI JW, NDANGALASI H, MBAGO F, BRUN R \& CHRISTENSEN SB. 2004. Ancistrotanzanine $C$ and Related 5, 1 '-and 7, 3 '-Coupled Naphthylisoquinoline Alkaloids from Ancistrocladus t anzaniensis. J Nat Prod 67: 743-748.

CEKER S, ORHAN F, KIZIL HE, ALPSOY L, GULLUCE M, ASLAN A \& AGAR G. 2015. Genotoxic and antigenotoxic potentials of two Usnea species. Toxicol Ind Health 31: 990-999.

CORDES E \& JENCKS W. 1962. On the mechanism of Schiff base formation and hydrolysis. J Am Chem Soc 84 : 832-837.

DHAR DN \& TAPLOO C. 1982. Schiff-bases and their applications. J Sci Ind Res 41: 501-506.

HALLING SM, PETERSON-BURCH BD, BRICKER BJ, ZUERNER RL, QING Z, LI L-L, KAPUR V, ALT DP \& OLSEN SC. 2005. Completion of the genome sequence of Brucella abortus and comparison to the highly similar genomes of Brucella melitensis and Brucella suis. J Bacteriol 187: 2715-2726.

METZLER DE, IKAWA M \& SNELL EE. 1954. A general mechanism for vitamin B6-catalyzed reactions1. I Am Chem Soc 76: 648-652.

MISHRA S, CHAUDHARI SR, LAKSHMIPRIYA A, PAL I, LOKESH N \& SURYAPRAKASH N 2017. Novel synthetic as well as natural auxiliaries with a blend of NMR methodological developments for chiral analysis in isotropic media. Annual Reports on NMR Spectroscopy: Elsevier, p. 143-292.

MOFFETT RB. 1963. Organic syntheses. n. 4, New York (USA): J Wiley \& Sons.

NARTOP D, NURSEN S \& HATICE O. 2014. Polymer-bound schiff bases and their $\mathrm{Cr}$ (III) complexes: synthesis, characterization, antibacterial and antifungal evaluation. Chinese J Inorg Chem 30: 921-929.

NARTOP D, SARI N, ALTUNDAŞ A \& ÖĞÜTCÜ H. 2012. Synthesis, characterization, and antimicrobial properties of new polystyrene-bound Schiff bases and their some complexes. J Appl Polym Sci 125: 1796-1803.

ORHAN F, ÇEKER S, ANAR M, AGAR G, ARASOGLU T \& GULLUCE M. 2016. Protective effects of three luteolin derivatives on aflatoxin B 1-induced genotoxicity on human blood cells. Med Chem Res 25: 2567-2577.

SARI N, PIŞKIN N, ÖĞÜTCÜ H \& KURNAZ N. 2013. Spectroscopic characterization of novel d-amino acid-Schiff bases and their $\mathrm{Cr}$ (III) and $\mathrm{Ni}$ (II) complexes as antimicrobial agents. Med Chem Res 22: 580-587.

SAURET JM \& VILISSOVA N. 2002. Human brucellosis. J Am Board Fam Pract 15: 401-406.

SINGH NP, MCCOY MT, TICE RR \& SCHNEIDER EL. 1988. A simple technique for quantitation of low levels of DNA damage in individual cells. Exp Cell Res 175: 184-191.

SNELL EE \& JENKINS WT. 1959. The mechanism of the transamination reaction. J Cell Physiol 54: 161-177.

ŞAKIYAN I, ANAR M, ÖĞÜTCÜ H, AGAR G \& SARI N. 2014. Schiff bases attached L-glutamine and L-asparagine: First investigation on antimutagenic and antimicrobial analyses. Artif Cells Nanomed Biotechnol 42: 199-204.

TANAK H, AĞAR AA \& BÜYÜKGÜNGÖR O. 2014. Experimental (XRD, FT-IR and UV-Vis) and theoretical modeling studies of Schiff base (E)-N'-((5-nitrothiophen-2-yl) methylene)2-phenoxyaniline. Spectrochim Acta A: Mol Biomol Spectrosc 118: 672-682.

ZABULICA A, BALAN M, BELEI D, SAVA M, SIMIONESCU BC \& MARIN L. 2013. Novel luminescent phenothiazine-based Schiff bases with tuned morphology. Synthesis, structure, photophysical and thermotropic characterization. Dyes Pigm 96: 686-698.

\section{How to cite}

OGUTCU H, MERAL S, CEKER S, AGAR AA \& AGAR G. 2021. Determination of antimicrobial and antimutagenic properties of some Schiff bases. An Acad Bras Cienc 93: e20191432. DOI 10.1590/0001-3765202120191432.

Manuscript received on November 26, 2019; accepted for publication on December 27, 2019 


\section{HATICE OGUTCU}

https://orcid.org/0000-0001-7100-9318

\section{SEHER MERAL ${ }^{2}$}

https://orcid.org/0000-0002-6309-8936

\section{SELCUK CEKER ${ }^{3}$}

https://orcid.org/0000-0002-2795-8863

\section{AYSEN ALAMAN AGAR}

https://orcid.org/0000-0002-1316-4835

\section{GULERAY AGAR ${ }^{5}$}

https://orcid.org/0000-0002-8445-5082

${ }^{1}$ Ahi Evran University, Faculty of Agriculture, Department of Field Crops, Kırsehir, Turkey

${ }^{2}$ Sinop University, Boyabat Vocational School, Department of Property Protection and Security, Sinop, Turkey

${ }^{3}$ Bolu Abant Izzet Baysal University, Faculty of Medicine, Department of Medical Biology, Bolu, Turkey
${ }^{4}$ Ondokuzmayıs University, Faculty of Arts and Sciences, Department of Chemistry, Samsun, Turkey

${ }^{5}$ Atatürk University, Faculty of Science,

Department of Biology, Erzurum, Turkey

Correspondence to: Selcuk Ceker

E-mail:selcukceker06@gmail.com

\section{Author contributions}

G.A., H.O., and A.A.A planned and conducted the research. S.M, S.C. and H.O provided tools and analyzed the data. G.A., H.O., and A.A.A wrote the manuscript with the contributions of other authors. All authors have read and approved the final manuscript.

(cc) BY 